\title{
Untangling the relationship between negative illness perceptions and worse quality of life in patients with advanced cancer-a study from the population-based PROFILES registry
}

\author{
Lea J. Jabbarian ${ }^{1}$ (D) Judith A. C. Rietjens ${ }^{1} \cdot$ Floortje Mols $^{2,3} \cdot$ Joost Oude Groeniger $^{1} \cdot$ Agnes van der Heide $^{1} \cdot$ \\ Ida J Korfage ${ }^{1}$
}

Received: 16 September 2020 / Accepted: 24 March 2021 / Published online: 23 April 2021

(C) The Author(s) 2021

\begin{abstract}
Purpose Quality of life (QoL) is an important yet complex outcome of care in patients with advanced cancer. QoL is associated with physical and psychosocial symptoms and with patients' illness perceptions (IPs). IPs are modifiable cognitive constructs developed to make sense of one's illness. It is unclear how IPs influence patients' QoL. A better understanding of this relationship can inform and direct high quality care aimed at improving patients' QoL. We therefore investigated the mediating role of anxiety and depression in the association of IPs with QoL.

Methods Data from 377 patients with advanced cancer were used from the PROFILES registry. Patients completed measures on IPs (BIPQ), QoL (EORTC QLQ-C30), and symptoms of anxiety and depression (HADS). Mediation analyses were conducted to decompose the total effect of IPs on QoL into a direct effect and indirect effect.

Results All IPs but one (“Comprehensibility”) were negatively associated with QoL ( $p<0.001)$; patients with more negative IPs tended to have worse QoL. The effect was strongest for patients who felt that their illness affected their life more severely ("Consequences"), patients who were more concerned about their illness ("Concern"), and patients who thought that their illness strongly affected them emotionally ("Emotions"). Anxiety mediated 41-87\% and depression mediated 39-69\% of the total effect of patients' IPs on QoL.

Conclusion Negative IPs are associated with worse QoL. Anxiety and depression mediate this association. Targeting symptoms of anxiety and depression, through the modification of IPs, has the potential to improve QoL of patients with advanced cancer.
\end{abstract}

Keywords Anxiety · Depression · Illness perceptions · Oncology · Quality of life

\section{Introduction}

Patients with advanced, incurable cancer experience an impaired quality of life (QoL) [1]. Their QoL is affected in a complex way by, among others, physical symptoms and psychological challenges [2], such as the confrontation with approaching death [3] and symptoms of anxiety and depression $[4,5]$. Whereas QoL is an important outcome of care, QoL is
Lea J. Jabbarian

1.jabbarian@erasmusmc.nl

Judith A. C. Rietjens

j.rietjens@erasmusmc.nl

Floortje Mols

F.Mols@uvt.nl

Joost Oude Groeniger

j.oudegroeniger@erasmusmc.nl

Agnes van der Heide

a.vanderheide@erasmusmc.nl
Ida J Korfage

i.korfage@ erasmusmc.nl

1 Department of Public Health, Erasmus MC, University Medical Center Rotterdam, P.O. Box 2040, 3000, CA Rotterdam, the Netherlands

2 Department of Medical and Clinical Psychology, Tilburg University, Tilburg, the Netherlands

Netherlands Comprehensive Cancer Organisation (IKNL), Netherlands Cancer Registry, Eindhoven, the Netherlands 
by definition multidimensional and subjective [2] and cannot be assessed by others, such as clinicians. Understanding which factors contribute to patients' QoL is therefore of utmost importance for the delivery of high quality care to patients with advanced cancer [6].

The so-called self-regulation model conceptualizes illness perceptions as important and well-established determinants of QoL [7, 8]. Illness perceptions are defined as cognitive constructs, developed by patients to make sense of and manage their illness experience [9, 10]. Patients can adjust their illness perceptions after receiving new information, e.g., regarding the progression of the disease, from healthcare providers, the media, friends, or family $[11,12]$. Illness perceptions can be in line with patients' actual medical situation, but they can also involve a distorted interpretation of medical facts [11]. A study among patients nearing death, including patients with advanced cancer, found a great variability in illness perceptions, indicating how differently patients perceive their illness [13]. These differences may be related to the individual's illness, cultural factors (such as the interpretation of the patient role, as well as the cultural interpretation of the illness) and factors related to an individual's personality [9]. Due to their modifiable nature, illness perceptions are a promising target for interventions aimed at improving patients' experiences of their illness and thereby their QoL $[8,14,15]$.

The relationship between illness perceptions and physical and psychological health has been investigated in various studies. A meta-analysis of 45 studies showed that the individual illness perceptions are associated with various outcomes of social, physical, and psychological functioning [7]. More specifically, for patients with a recent cancer diagnosis, illness perceptions predicted QoL 15 months postdiagnosis, e.g., patients who thought that their cancer diagnosis had a more serious negative consequence for, among others, their relationships and finances, later reported poorer QoL [8]. While the effects of illness perceptions on QoL have been described and are recognized [8, 14, 15], there is little insight into the mechanisms underlying this relationship. Understanding these mechanisms can guide the development of future interventions aimed at the improvement of patients' QoL. Previous research hypothesized a mediating role of anxiety and depression, since these are associated with both illness perceptions and QoL [16, 17], and are particularly common in patients with advanced cancer [18, 19]. We therefore performed a study to clarify the relationship between illness perceptions and QoL, with symptoms of anxiety and depression as potential mediators, in patients with advanced cancer, accounting for interaction effects between the illness perceptions and the mediators.

\section{Materials and methods}

\section{Participants and data collection}

The data were derived from the 'Patient Reported Outcomes Following Initial treatment and Long term Evaluation of Survivorship' (PROFILES) registry. This registry includes data to study the physical and psychosocial impact of cancer and its treatment. PROFILES is linked to the Eindhoven Cancer Registry (ECR), which includes all patients newly diagnosed with cancer in the southern part of the Netherlands. To check whether patients are still alive, these data are merged with civil municipal registries and subsequently verified by (former) treating physicians. Patients with serious cognitive impairments or in transition to terminal care are excluded. The remaining patients are invited via mail by their (former) treating physician to participate in the PROFILES registry. Interested patients can provide informed consent and complete the questionnaires via a secure website, or on paper. Patients receive questionnaires between one and four times a year. They must be able to read and write Dutch and complete a self-report questionnaire without extensive assistance. The rationale and design of PROFILES have been described elsewhere [20], data and detailed information can be found at www.profilesregistry.nl. Ethical approval for the data collection was obtained from local certified Medical Ethics Committees of the Maxima Medical Centre Veldhoven, the Netherlands (colorectal cancer, approval number 0822), the certified Medical Ethics Committee of the Maxima Medical Centre, the Netherlands ((non)Hodgkin lymphoma) and deemed exempt from full review and approval by the Research Ethics Committee Maxima Medical Centre, Veldhoven, the Netherlands (thyroid cancer). Informed consent was obtained from all individual participants included in the study. We used data from adult patients diagnosed with stage IV (non)Hodgkin lymphoma, stage IV colorectal cancer, or stage IV thyroid cancer, without cognitive impairments $(n=377)$.

\section{Measures}

\section{Sociodemographic and clinical characteristics}

The PROFILES registry includes the patient sociodemographic characteristics gender, age at the time of survey and at the time of diagnosis (automatically divided into $\leq 40$ or $>40$ years), and time passed since the diagnosis ( $<2$ or $\geq 2$ years). Socioeconomic status was assessed using an indicator developed by Statistics Netherlands, based on the postal code of the residential address of the patient [21]. The registry includes the clinical characteristic tumor subtype. Patients completed the Self-administered Comorbidity Questionnaire [22]. 


\section{Illness perceptions}

The Brief Illness Perception Questionnaire (BIPQ) [23] is frequently used in cancer populations[24] and has good psychometric properties [25]. The BIPQ consists of eight items, each addressing a specific illness perception that is scored on a tenpoint scale [23]:

Consequences: "How much does your illness affect your life?"

(0-"No affect at all" to 10 - "Severely affects my life")

Timeline: "How long do you think your illness will continue?"

( 0 - "A very short time" to 10 - "Forever")

Personal control: "How much control do you feel you have over your illness"?

(0- "Absolutely no control" to 10 - "Extreme amount of control")

Treatment control: "How much do you think your treatment can help your illness?"

(0- "Not at all" to 10 - "Extremely helpful")

Identity: "How much symptoms do you experience from your illness?"

(0- "No symptoms at all" to 10- "Many severe symptoms")

Concerns:"How concerned are you about your illness?"

(0- "Not at all concerned" to 10- "Extremely

concerned")

Emotions: "How much does your illness affect you emotionally?"

(0- "Not at all affected emotionally" to

10 - "Extremely affected emotionally")

Comprehensibility: "How well do you understand your illness?"

(0 "Don't understand at all" to 10 - "Understand very clearly")

For the statistical analyses, we recoded the responses of three items (personal control, treatment control, and comprehensibility) to be in the same direction as the other items. Higher scores imply more negative illness perceptions (e.g., experiencing more symptoms due to the illness or being more concerned about the illness).

\section{Health-related quality of life}

The European Organisation for Research and Treatment of Cancer (EORTC) Quality of Life Questionnaire Core 30 (QLQ-C30; version 3.0) is an often used, validated 30-item self-reported questionnaire that contains five functional scales, three symptom scales, and six single items [26]. We calculated the recently developed QLQ-C30 summary score (range 0100) [27]. A higher score indicates better QoL.

\section{Symptoms of anxiety and depression}

The Hospital Anxiety and Depression Scale (HADS) is a widely used self-reported questionnaire that measures levels of anxiety (HADS-A: seven items) and depression (HADS-D: seven items) of patients during the past week [28]. The HADS has shown good psychometric properties in various samples and settings [29]. The items are scored on a four-point Likertscale (range total score for each subscale 0-21). A score of 8 or higher on the subscales (HADS-A and HADS-D) indicates mild to severe symptoms of anxiety or depression [29].

\section{Statistical analyses}

Pearson correlation analyses were used to examine bivariate associations of illness perceptions, with anxiety and depression and QoL. From the original PROFILES registry, we selected the 377 patients who were diagnosed with advanced cancer. We conducted the mediation analyses with complete cases. Missing data varied from $0 \%$ for gender to $28 \%$ for comorbid conditions (Tables 1 and 2). Among the 377 patients in the total sample, 216 (57\%) to 224 (59\%), depending on the exposure, provided full information on the exposure (illness perceptions), mediator (anxiety or depression), outcome variable (QoL), and confounders (tumor subtype, gender, age at time of diagnosis ( $\leq 40$ or $>40$ years), time passed since diagnosis ( $<2$ or $\geq 2$ years), socioeconomic status (low, medium, high, living in care institutions), and the number of comorbidities (none, $1, \geq 2$ ).

The aim of this study was to estimate how much of the observed associations of illness perceptions (exposure variables) with QoL (outcome variable) could be explained by anxiety or depression (mediators). Figure $1 \mathrm{a}$ and $\mathrm{b}$ depicts the hypothesized associations. The analyses were controlled for confounders, which were patient characteristics that, based on literature [30] and a priori assumptions, were suspected to have an impact on illness perceptions and QoL: tumor subtype, gender, age at time of diagnosis ( $\leq 40$ or $>40$ years), time passed since diagnosis ( $<2$ or $\geq 2$ years), socioeconomic status (low, medium, high, living in care institutions), and the number of comorbidities (none, $1, \geq 2$ ). We found interaction effects between half of the illness perceptions and anxiety and depression on QoL. In the presence of interaction effects between exposure and mediator, traditional mediation methods such as the commonly used Baron and Kenny method, will generate invalid mediation effects $[31,32]$. We therefore used a novel approach as described by Valeri and VanderWeele, which allows for exposure-mediator interactions [32]. A detailed description of this method is included in Box 1. 
Box 1 Mediation analysis by Valeri and VanderWeele

Using the counterfactual framework, the Valeri and VanderWeele method is able to decompose the estimated total effect of an exposure on an outcome into a natural direct effect (i.e. the effect of illness perceptions on QoL that occurs without mediation) and a natural indirect effect (i.e. the effect of illness perceptions on QoL that is mediated by symptoms of anxiety and depression). The percentage mediation was calculated by dividing the natural indirect effect by the total effect.

In the mediation analyses, the illness perceptions scores were standardized and natural direct and natural indirect effects were calculated by comparing the mean level of an illness perception score to the mean +1 standard deviation [SD]. The estimated total effect thus expresses the change in QoL if an mediator, anxiety or depression, is kept at the level it would have taken at the mean level of the illness perception. The natural indirect effect expresses the change in QoL if an illness perception score is kept stable at mean $+1 \mathrm{SD}$, while the mediator score changes from the level it would take at the mean level of the illness perception to the level it would take at the mean +1 SD level of the illness perception.

Using the counterfactual framework, the Valeri and VanderWeele method is able to decompose the estimated total effect of an exposure on an outcome into a natural direct effect (i.e., the effect of illness perceptions on QoL that occurs without mediation) and a natural indirect effect (i.e., the effect of illness perceptions on QoL that is mediated by symptoms of anxiety and depression). The percentage mediation was calculated by dividing the natural indirect effect by the total effect.

In the mediation analyses, the illness perceptions scores were standardized and natural direct and natural indirect effects were calculated by comparing the mean level of an illness perception score to the mean +1 standard deviation [SD]. The estimated total effect thus expresses the change in QoL if an illness perception score increases from the mean to the mean +1 SD. The natural direct effect expresses the change in QoL if an illness perception score increases from the mean to the mean $+1 \mathrm{SD}$, while the

Analyses were performed using SPSS version 21. The mediation analyses were performed using Stata version 13 with the package 'Paramed'. $p$ values $<0.05$ were considered to indicate statistically significant associations. 95\% confidence intervals were automatically generated by the package 'Paramed' (based on the delta method) around the estimated total effect, natural direct effect, and natural indirect effect.

\section{Results}

\section{Patient sample}

The majority of patients in our sample $(n=377)$ were male $(60 \%)$, older than 40 years at diagnosis (92\%), and diagnosed with cancer two or more years prior to participation in the study ( $80 \%$, Table 1). Two or more comorbid conditions were reported by $36 \%$ of patients.

The mean summary score of the QLQ-C30 was 83.1 (SD 15.7, Table 2). Mean scores on the BIPQ are presented in Table 2. Mild to severe symptoms of anxiety were reported by $26 \%$ of patients and $25 \%$ of patients reported mild to severe symptoms of depression. All but one ("Comprehensibility") of the illness perceptions were negatively and significantly associated with QoL $(p<0.001)$, indicating that negative illness perceptions were associated with worse QoL (Table 2).

\section{Mediation analysis}

Anxiety as a mediator of the association of illness perceptions with quality of life

Having more negative illness perceptions was associated with more symptoms of anxiety and having more symptoms of anxiety was associated with worse QoL. The total effect on 
Table 1 Sociodemographic and clinical characteristics $(n=377)$

\begin{tabular}{ll}
\hline & No. $(\%)$ \\
\hline Gender & \\
Male & $227(60.2)$ \\
Female & $150(39.8)$ \\
Age at time of survey & \\
$\leq 40$ years & $16(4.6)$ \\
$>40$ years & $334(95.4)$ \\
Tumor subtype & \\
Non-Hodgkin lymphoma & $52(13.8)$ \\
Hodgkin lymphoma & $192(50.9)$ \\
Colorectal cancer & $114(30.2)$ \\
Thyroid cancer & $19(5.0)$ \\
Age at time of diagnosis & \\
$\leq 40$ years & $29(8.3)$ \\
$>40$ years & $322(91.7)$ \\
Years since diagnosis & \\
$<2$ years & $77(20.5)$ \\
$\geq 2$ years & $299(79.5)$ \\
Comorbid conditions & \\
0 & $95(35.2)$ \\
1 & $78(28.9)$ \\
$\geq 2$ & $97(35.9)$ \\
Socioeconomic status & $131(38.2)$ \\
Mow & $123(35.9)$ \\
High & $3(0.9)$ \\
\hline Living in a care institution & \\
\hline & \\
\hline & \\
\hline & \\
\hline &
\end{tabular}

Missings: age at survey $n=27$, age at diagnosis $n=26$, years since diagnosis $n=1$, comorbidity $n=107$, socioeconomic status $n=34$

QoL was largest for the illness perceptions "Consequences" (perceived effects and outcome of the illness on a patient's life), "Identity" (experience of symptoms due to the illness),
Table 2 Quality of life, illness perceptions, anxiety and depression: summary scores and correlations

\begin{tabular}{lll}
\hline & Mean (SD) & $\begin{array}{l}\text { Pearson's correlation } \\
\text { coefficients }\end{array}$ \\
\hline Quality of life (EORTC QLQ-C30) & \\
Quality of life & $83.11(15.70)$ & 1.00 \\
Illness perceptions (BIPQ) & & \\
Consequences & $4.97(2.64)$ & $-.49^{*}$ \\
Timeline & $6.94(3.41)$ & $-.17^{* *}$ \\
Personal control & $5.82(3.13)$ & $-.21^{* *}$ \\
Treatment control & $3.77(2.61)$ & $-.34^{* *}$ \\
Identity & $4.47(2.70)$ & $-.55^{* *}$ \\
Concerns & $4.97(2.76)$ & $-.17^{* *}$ \\
Emotions & $4.21(2.59)$ & $-.46^{* *}$ \\
Comprehensibility & $3.89(2.71)$ & -.05 \\
Anxiety and depression (HADS) & \\
Anxiety & $5.10(4.07)$ & $-.63^{* *}$ \\
Depression & $4.86(3.98)$ & $-.68^{* *}$ \\
\hline
\end{tabular}

Missings: quality of life $n=8$, consequences $n=62$, timeline $n=54$, personal control $n=46$, treatment $n=51$, identity $n=45$, concerns $n=41$, emotions $n=43$, comprehensibility $n=40$, anxiety $n=10$, depression $n=11$

Abbreviations: $S D$, standard deviation; EORTC, European Organisation for Research and Treatment, $O L Q-C 30$, Quality of Life Questionnaire Core 30; $B I P Q$, Brief Illness Perception Questionnaire; HADS, Hospital Anxiety and Depression Scale

$* p<0.05$. ** $p<0.01$

"Concerns" (extent to which the patient is concerned about the illness) and "Emotions" (emotional impact of the illness). A total of 41 to $87 \%$ of the total effect of the different illness perceptions was mediated by anxiety (Table 3 ). The mediating effect of anxiety was strongest for the illness perception "Emotions". The total effect of the illness perception "Timeline" (how long the patient believes that the illness will last) on QoL, which was limited, was to a relatively large extent (84\%) mediated by anxiety.
Fig. 1 Mediation model depicting the association of illness perceptions with quality of life mediated by $\mathbf{a}$ anxiety and $\mathbf{b}$ depression

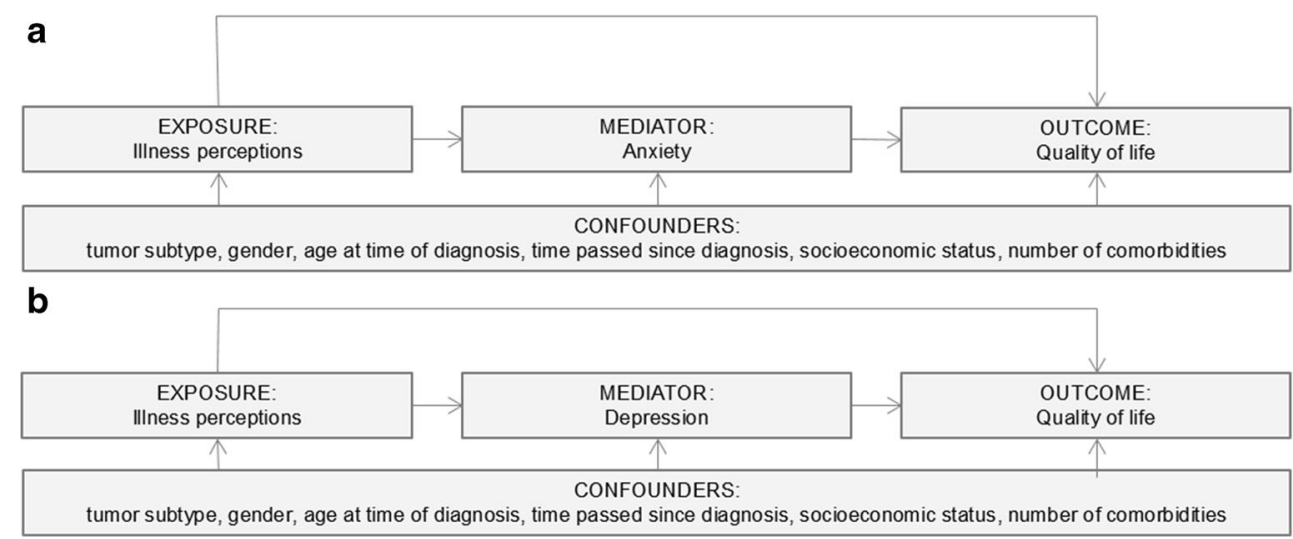


Table 3 Illness perceptions and quality of life: natural direct effect and indirect effect mediated by anxiety

\begin{tabular}{|c|c|c|c|c|c|c|c|c|c|c|}
\hline & \multicolumn{3}{|c|}{ Total effect } & \multicolumn{3}{|c|}{ Natural direct effect } & \multicolumn{3}{|c|}{ Natural indirect effect } & \multirow{2}{*}{$\begin{array}{l}\text { Percentage mediation } \\
\%\end{array}$} \\
\hline & Estimate & $95 \% \mathrm{CI}$ & $p$ & Estimate & $95 \% \mathrm{CI}$ & $p$ & Estimate & $95 \% \mathrm{CI}$ & $p$ & \\
\hline \multicolumn{11}{|l|}{ Illness perceptions } \\
\hline (1) Consequences $(n=216)$ & -8.65 & $-1.74,-6.57$ & .000 & -4.60 & $-6.44,-2.76$ & .000 & -4.05 & $-5.52,-2.59$ & .000 & $47 \%$ \\
\hline $\begin{array}{l}\text { (2) Timeline } \\
(n=216)\end{array}$ & -1.80 & $-3.87, .27$ & .088 & -.28 & $-2.01,1.44$ & .747 & -1.52 & $-2.66,-.37$ & .009 & $84 \%$ \\
\hline $\begin{array}{l}\text { (3) Personal control } \\
(n=223)\end{array}$ & -3.12 & $-5.18,-1.05$ & .003 & -1.04 & $-2.73, .65$ & .228 & -2.08 & $-3.32,-.83$ & .001 & $67 \%$ \\
\hline $\begin{array}{l}\text { (4) Treatment control } \\
(n=219)\end{array}$ & -5.48 & $-7.53,-3.43$ & .000 & -2.91 & $-4.63,-1.2$ & .001 & -2.56 & $-3.89,-1.24$ & .000 & $47 \%$ \\
\hline $\begin{array}{l}\text { (5) Identity } \\
(n=220)\end{array}$ & -7.81 & $-9.71,-5.92$ & .000 & -4.61 & $-6.32,-2.89$ & .000 & -3.21 & $-4.48,-1.94$ & .000 & $41 \%$ \\
\hline $\begin{array}{l}\text { (6) Concerns } \\
(n=223)\end{array}$ & -7.03 & $-9.1,-4.96$ & .000 & -1.95 & $-4, .09$ & .062 & -5.08 & $-6.73,-3.44$ & .000 & $72 \%$ \\
\hline $\begin{array}{l}\text { (7) Emotions } \\
(n=224)\end{array}$ & -6.43 & $-8.29,-4.57$ & .000 & -.86 & $-3.09,1.36$ & .446 & -5.57 & $-7.34,-3.79$ & .000 & $87 \%$ \\
\hline $\begin{array}{l}\text { (8) Comprehensibility }{ }^{\mathrm{a}} \\
(n=222)\end{array}$ & -.37 & $-2.32,1.58$ & .708 & .80 & $-.85,2.44$ & .344 & -1.17 & $-2.3,-.04$ & .042 & \\
\hline
\end{tabular}

${ }^{a}$ Comprehensibility affects quality of life via opposing direct and indirect effects. This makes calculating the mediated effect nonsensical

\section{Depression as a mediator of the association of illness perceptions with quality of life}

Having more negative illness perceptions was associated with more symptoms of depression, which, in turn, was associated with worse QoL. Depression mediated 39 to $69 \%$ of the effect of illness perceptions on QoL (Table 4).
The mediating effects of depression were strongest for the illness perceptions "Emotions", "Concerns", and "Consequences". The limited total effect of the illness perception "Timeline" on QoL was to relatively large extent $(69 \%)$ mediated by depression. In general, the mediating effects of depression were somewhat weaker than the mediating effects of anxiety.

Table 4 Illness perceptions and quality of life: natural direct effect and indirect effect mediated by depression

\begin{tabular}{|c|c|c|c|c|c|c|c|c|c|c|}
\hline & \multicolumn{3}{|c|}{ Total effect } & \multicolumn{3}{|c|}{ Natural direct effect } & \multicolumn{3}{|c|}{ Natural indirect effect } & \multirow{2}{*}{$\begin{array}{l}\text { Percentage mediation } \\
\%\end{array}$} \\
\hline & Estimate & $95 \% \mathrm{CI}$ & $p$ & Estimate & $95 \% \mathrm{CI}$ & $p$ & Estimate & $95 \% \mathrm{CI}$ & $p$ & \\
\hline \multicolumn{11}{|l|}{ Illness perceptions } \\
\hline $\begin{array}{l}\text { (1) Consequences } \\
(n=216)\end{array}$ & -8.02 & $-1.01,-6.04$ & .000 & -4.19 & $-5.95,-2.43$ & .000 & -3.83 & $-5.25,-2.41$ & .000 & $48 \%$ \\
\hline $\begin{array}{l}\text { (2) Timeline } \\
(n=216)\end{array}$ & -2.08 & $-4.16, .01$ & .051 & -.64 & $-2.29,1.01$ & .447 & -1.44 & $-2.71,-.16$ & .028 & $69 \%$ \\
\hline $\begin{array}{l}\text { (3) Personal control } \\
(n=223)\end{array}$ & -2.98 & $-4.98,-.98$ & .003 & -1.27 & $-2.86, .33$ & .119 & -1.71 & $-2.97,-.46$ & .007 & $57 \%$ \\
\hline $\begin{array}{l}\text { (4) Treatment control } \\
(n=219)\end{array}$ & -5.45 & $-7.48,-3.41$ & .000 & -2.68 & $-4.35,-1.01$ & .002 & -2.77 & $-4.14,-1.39$ & .000 & $51 \%$ \\
\hline $\begin{array}{l}(5) \text { Identity } \\
(n=220)\end{array}$ & -7.70 & $-9.59,-5.81$ & .000 & -4.71 & $-6.31,-3.11$ & .000 & -2.99 & $-4.28,-1.71$ & .000 & $39 \%$ \\
\hline $\begin{array}{l}\text { (6) Concerns } \\
(n=223)\end{array}$ & -6.81 & $-8.8,-4.81$ & .000 & -2.88 & $-4.63,-1.13$ & .001 & -3.93 & $-5.36,-2.49$ & .000 & $58 \%$ \\
\hline $\begin{array}{l}\text { (7) Emotions } \\
(n=224)\end{array}$ & -6.72 & $-8.62,-4.83$ & .000 & -2.79 & $-4.48,-1.1$ & .001 & -3.94 & $-5.33,-2.54$ & .000 & $59 \%$ \\
\hline $\begin{array}{l}\text { (8) Comprehensibility } \\
(n=222)\end{array}$ & -.35 & $-2.28,1.58$ & .723 & .97 & $-.63,2.56$ & .235 & -1.32 & $-2.49,-.14$ & .028 & \\
\hline
\end{tabular}

${ }^{a}$ Comprehensibility effects quality of life via opposing direct and indirect effects. This makes calculating the mediated effect nonsensical 


\section{Discussion}

This study explored the mediating role of anxiety and depression in the association of illness perceptions with QoL in a large sample of patients with advanced cancer. We were able to confirm prior findings that having more negative illness perceptions (e.g., experiencing more symptoms due to the illness, being more concerned about the illness) is associated with worse QoL. Our study adds that this association is substantially mediated by symptoms of anxiety or depression.

It is not surprising that the total effect of the illness perception "Emotions" (emotional impact of the illness) on QoL was the largest and to a relatively large extent mediated by symptoms of anxiety and depression, considering that this item measures the emotional impact of the illness on the patient. In accordance with previous research among patients treated for breast cancer [33], we found that patients who feel that their illness affects their life more severely ("Consequences") and who experience many symptoms from their illness ("Identity") have a considerable worse QoL. Our findings add that nearly half of that association was mediated by symptoms of anxiety or depression. Patients scoring high on "Identity" tend to attribute commonly occurring symptoms (such as a headache) to their illness, even if no such association exists [34]. This applies in particular to patients with advanced cancer who have to deal with uncertainty about the extent to which their life expectancy is limited and who tend to interpret symptoms as signs of potential progression of their illness $[35,36]$. We now know that over-interpretation of symptoms may lead to symptoms of anxiety and depression, which in turn impairs QoL.

Patients had the highest average score on the illness perception "Timeline", meaning that they believed that their illness would last "forever". Previous research has shown that "Timeline" scores were skewed toward the upper extreme in patients with advanced cancer, which suggests awareness of the incurable nature of their illness [13]. "Timeline" scores were only to a limited extent associated with QoL. This association however was to a large extent mediated by symptoms of anxiety and depression, meaning that being aware of the limited life expectancy does not have a strong direct effect on QoL itself, but mainly impacts QoL negatively through the strong experience of symptoms of anxiety and depression.

Understanding how patients with advanced cancer make sense of their diagnosis and addressing these illness perceptions is a promising approach when supporting patients with symptoms of anxiety or depression, and can thus be a way of improving the QoL of patients with advanced cancer. Since the prevalence of symptoms of anxiety and depression is higher in patients with advanced cancer than in colorectal cancer survivors, and even higher in comparison to the normative population [37], patients are in clear need of support. Our findings emphasize the importance of raising awareness for patients' illness perceptions [38, 39], especially since previous research found that healthcare providers' understanding of the illness perceptions of their patients was relatively poor [40], also with regard to important topics such as prognosis [41]. The recent consensus guideline of the American Society of Clinical Oncology on patient-clinician communication highlights the importance of (improved) health care communication and its positive impact on many objective and subjective health outcomes [38]. Incorporating the discussion of illness perceptions may play an important role in the patient-clinician communication and in meeting patients' information needs [30]. Additionally, previous research indicated the usefulness of targeting illness perceptions as a way to improve health outcomes [42]. Patients who were recovering from a myocardial infarction found a brief intervention on altering illness perceptions to be effective in improving functional outcomes [42]. Moreover, a recent study with patients with unruptured intracranial aneurysm found that cognitive behavioral therapy reduces feelings of anxiety and improves illness perceptions [43]. Given that cognitive behavioral therapy has been proven effective in the treatment of mood disorders in patients with cancer, it would be worthwhile to investigate its application in patients with (advanced) cancer [44].

The main strengths of this study lie in the use of a relatively large dataset of patients with advanced cancer, a unique and vulnerable group of patients that is rarely investigated, and the use of recently developed, advanced mediation analysis techniques that allow for the decomposition of total effects into natural direct and indirect effects, while accounting for exposure-mediator interactions.

Some limitations need to be considered when interpreting the findings. Although previous research and theoretical models suggest a strong temporal sequence, with illness perceptions preceding symptoms of anxiety and depression [17], this study cannot draw causal conclusions due to its crosssectional study design. Second, to interpret the observed direct and indirect effects, one needs to assume that there are no unmeasured confounders of the exposure-mediator relationship, the mediator-outcome relationship and the exposureoutcome relationship [32]. Although we did adjust for several potential confounders, we cannot exclude the possibility that unmeasured confounders may have impacted the results. Third, we performed a complete case analysis on the subset of patients with full information on the exposure, mediator, outcome variables and confounders. While this method is widely applied to treat missing data, it may lead to biased results if the data are not missing completely at random [45].

In conclusion, our study indicates that negative illness perceptions are associated with worse QoL in patients with advanced cancer. Symptoms of anxiety and depression substantially mediate this association. Applying this knowledge to patient-clinician interactions may improve its quality and ultimately the QoL of patients with advanced cancer. Further 
prospective research is needed to confirm these findings and extend the exploration of hidden mechanisms behind the relationship between illness perceptions and QoL, by looking at the role of e.g., personality traits and coping styles, physical factors such as comorbidities and different types and stages of cancer, health literacy, cultural factors, or the quality of patient-clinician interactions. QoL and symptoms of anxiety and depression in patients with advanced cancer may be improved by addressing illness perceptions during medical consultations.

Acknowledgements We would like to thank all patients for participating in this study. We would like to express our gratitude to the team of the PROFILES registry for building up this registry and allowing researchers to access and use the data.

Code availability Not applicable.

Data availability Data and detailed information can be found at www. profilesregistry.nl.

\section{Declarations}

Ethics approval Ethical approval for the data collection was obtained from locally certified Medical Ethics Committees of the Maxima Medical Centre Veldhoven, the Netherlands (colorectal cancer, approval number 0822), the certified Medical Ethics Committee of the Maxima Medical Centre, the Netherlands ((non)Hodgkin lymphoma), and deemed exempt from full review and approval by the Research Ethics Committee Maxima Medical Centre, Veldhoven, the Netherlands (thyroid cancer).

Consent to participate Informed consent was obtained from all individual participants included in the study.

Consent for publication Not applicable.

Competing interests The authors declare no competing interests.

Open Access This article is licensed under a Creative Commons Attribution 4.0 International License, which permits use, sharing, adaptation, distribution and reproduction in any medium or format, as long as you give appropriate credit to the original author(s) and the source, provide a link to the Creative Commons licence, and indicate if changes were made. The images or other third party material in this article are included in the article's Creative Commons licence, unless indicated otherwise in a credit line to the material. If material is not included in the article's Creative Commons licence and your intended use is not permitted by statutory regulation or exceeds the permitted use, you will need to obtain permission directly from the copyright holder. To view a copy of this licence, visit http://creativecommons.org/licenses/by/4.0/.

\section{References}

1. Higginson IJ, Costantini M (2008) Dying with cancer, living well with advanced cancer. Eur J Cancer 44(10):1414-1424

2. Organization, W.H (1994) Quality of life assessment: an annotated bibliogrpahy. WHO (WHO/MNH/PSD/94.1), Geneva

3. Walsh $\mathrm{C}$ et al (2017) Coping well with advanced cancer: a serial qualitative interview study with patients and family carers. PLoS ONE 12(1)
4. Pirl WF (2004) Evidence report on the occurrence, assessment, and treatment of depression in cancer patients. J Natl Cancer Inst Monogr 32:32-39

5. Carr D, G.L., Lawrence D, et al., Management of cancer symptoms: pain, depression, and fatigue. Evidence Report/Technology Assessment No. 61 (Prepared by the New England Medical Center Evidence-based Practice Center under Contract No 29097-0019). 2002, Rockville, MD: Agency for Healthcare Research and Quality.

6. van Roij J et al (2018) Measuring health-related quality of life in patients with advanced cancer: a systematic review of selfadministered measurement instruments. Qual Life Res

7. Hagger MS, Orbell S (2003) A Meta-analytic review of the common-sense model of illness representations. Psychol Health 18(2):141-184

8. Ashley L, Marti J, Jones H, Velikova G, Wright P (2015) Illness perceptions within 6 months of cancer diagnosis are an independent prospective predictor of health-related quality of life 15 months post-diagnosis. Psychooncology 24(11):1463-1470

9. Leventhal H, Diefenbach M, Leventhal E (1992) illness cognition: using common sense to understand treatment adherence and affect cognition interactions. Cogn Ther Res 16(2):143-163

10. Leventhal H, B.I., Leventhal EA, The common-sense model of selfregulation of health \& illness, in The self-regulation of health \& illness behaviour, L.H. Cameron LD, Editor. 2003, Routledge Taylor \& Francis Group: London. p. 42-60

11. Donovan H, Ward S (2001) A representational appraoch to patient education. J Nurs Scholarsh 33(3):211-216

12. Kissane DW, Bylund CL, Banerjee SC, Bialer PA, Levin TT, Maloney EK, D'Agostino TA (2012) Communication skills training for oncology professionals. J Clin Oncol 30(11):1242-1247

13. Price A, Goodwin L, Rayner L, Shaw E, Hansford P, Sykes N, Monroe B, Higginson I, Hotopf M, Lee W (2012) Illness perceptions, adjustment to illness, and depression in a palliative care population. J Pain Symptom Manag 43(5):819-832

14. Thong MS et al (2016) Illness perceptions are associated with mortality among 1552 colorectal cancer survivors: a study from the population-based PROFILES registry. J Cancer Surviv 10(5): 898-905

15. Keogh KM, Smith S, White P, McGilloway S, Kelly A, Gibney J, O'Dowd T (2011) Psychological family intervention for poorly controlled type 2 diabetes. Am J Manag Care 17(2):105-113

16. Smith EM, Gomm S, Dickens CM (2003) Assessing the independent contribution to quality of life from anxiety and depression in patients with advanced cancer. Palliat Med 17:509-513

17. Morgan K, Villiers-Tuthill A, Barker M, Mcgee H (2014) The contribution of illness perception to psychological distress in heart failure patients. BMC Psychol 2:50

18. Brown LF, Kroenke K, Theobald DE, Wu J, Tu W (2010) The association of depression and anxiety with health-related quality of life in cancer patients with depression and/or pain. Psychooncology 19(7):734-741

19. Stark D, Kiely M, Smith A, Velikova G, House A, Selby P (2002) Anxiety disorders in cancer patients: their nature, associations, and relation to quality of life. J Clin Oncol 20(14):3137-3148

20. van de Poll-Franse LV et al (2011) The patient reported outcomes following initial treatment and long term evaluation of survivorship registry: scope, rationale and design of an infrastructure for the study of physical and psychosocial outcomes in cancer survivorship cohorts. Eur J Cancer 47(14):2188-2194

21. van Duijn C (2002) K.I., Sociaal-economische status indicator op postcode niveau [in Dutch]. Maandstatistiek van de bevolking 50: 32-35

22. Sangha O, Stucki G, Liang MH, Fossel AH, Katz JN (2003) The Self-Administered Comorbidity Questionnaire: a new method to 
assess comorbidity for clinical and health services research. Arthritis Rheum 49(2):156-163

23. Broadbent E, Petrie KJ, Main J, Weinman J (2006) The brief illness perception questionnaire. J Psychosom Res 60(6):631-637

24. Kaptein AA, Yamaoka K, Snoei L, van der Kloot WA, Inoue K, Tabei T, Kroep JR, Krol-Warmerdam E, Ranke G, Meirink C, Does A, Nortier H (2013) Illness perceptions and quality of life in Japanese and Dutch women with breast cancer. J Psychosoc Oncol 31(1):83-102

25. Broadbent E, Wilkes C, Koschwanez H, Weinman J, Norton S, Petrie KJ (2015) A systematic review and meta-analysis of the Brief Illness Perception Questionnaire. Psychol Health 30(11): 1361-1385

26. Niezgoda HE, Pater J (1993) A validation study of the domains of the core EORTC quality of life questionnaire. Qual Life Res 2(5): 319-325

27. Giesinger JM, Kieffer JM, Fayers PM, Groenvold M, Petersen MA, Scott NW, Sprangers MA, Velikova G, Aaronson NK, EORTC Quality of Life Group (2016) Replication and validation of higher order models demonstrated that a summary score for the EORTC QLQ-C30 is robust. J Clin Epidemiol 69:79-88

28. Zigmond AS, Snaith R (1983) The Hospital Anxiety and Depression Scale. Acta Psychiatr Scand 67:631-370

29. Bjelland I, Dahl AA, Haug TT, Neckelmann D (2002) The validity of the Hospital Anxiety and Depression Scale. An updated literature review. J Psychosom Res 52(2):69-77

30. Husson O, Thong MSY, Mols F, Oerlemans S, Kaptein AA, van de Poll-Franse LV (2013) Illness perceptions in cancer survivors: what is the role of information provision? Psychooncology 22(3):490 498

31. Baron RM, Kenny D (1986) The moderator-mediator variable distinction in social psychological research: conceptual, strategic, and statistical considerations. J Pers Soc Psychol 51(6):1173-1182

32. Valerie L, VanderWeele TJ (2013) Mediation analysis allowing for exposure-mediation interactions and causal interpretation: theoretical assumptions and implementation with SAS and SPSS macros. Psychol Methods 18(2):137-150

33. Rozema H, Vollink T, Lechner L (2009) The role of illness representations in coping and health of patients treated for breast cancer. Psychooncology 18(8):849-857

34. Petrie KJ, Weinman J (2006) Why illness perceptions matter. Clin Med 6:536-539

35. Etkind SN, Bristowe K, Bailey K, Selman LE, Murtagh FEM (2017) How does uncertainty shape patient experience in advanced illness? A secondary analysis of qualitative data. Palliat Med 31(2): 171-180

36. Lobb EA, Lacey J, Kearsley J, Liauw W, White L, Hosie A (2015) Living with advanced cancer and an uncertain disease trajectory: an emerging patient population in palliative care? BMJ Support Palliat Care 5(4):352-357

37. Mols F, Schoormans D, de Hingh I, Oerlemans S, Husson O (2018) Symptoms of anxiety and depression among colorectal cancer survivors from the population-based, longitudinal PROFILES Registry: prevalence, predictors, and impact on quality of life. Cancer 124(12):2621-2628

38. Gilligan T, Coyle N, Frankel RM, Berry DL, Bohlke K, Epstein RM, Finlay E, Jackson VA, Lathan CS, Loprinzi CL, Nguyen LH, Seigel C, Baile WF (2017) Patient-clinician communication: American Society of Clinical Oncology Consensus Guideline. J Clin Oncol 35:3618-3632

39. Kus T, Aktas G, Ekici H, Elboga G, Djamgoz S (2017) Illness perception is a strong parameter on anxiety and depression scores in early-stage breast cancer survivors: a single-center cross-sectional study of Turkish patients. Support Care Cancer 25(11):33473355

40. Street RL Jr, Haidet P (2011) How well do doctors know their patients? Factors affecting physician understanding of patients' health beliefs. J Gen Intern Med 26(1):21-27

41. Gramling R, Fiscella K, Xing G, Hoerger M, Duberstein P, Plumb S, Mohile S, Fenton JJ, Tancredi DJ, Kravitz RL, Epstein RM (2016) Determinants of patient-oncologist prognostic discordance in advanced cancer. JAMA Oncol 2(11):1421-1426

42. Petrie KJ, Cameron L, Ellis CJ, Buick D, Weinman J (2002) Changing illness perceptions after myocardial infarction: an early intervention randomized controlled trial. Psychosom Med 64:580 586

43. Lemos M, Román-Calderón JP, Restrepo J, Gómez-Hoyos JF, Jimenez CM (2020) Cognitive behavioral therapy reduces illness perceptions and anxiety symptoms in patients with unruptured intracranial aneurysm. J Clin Neurosci 80:56-62

44. Hopko DR, Bell J, Armento M, Robertson S, Mullane C, Wolf N, Lejuez CW (2008) Cognitive-behavior therapy for depressed cancer patients in a medical care setting. Behav Ther 39(2):126-136

45. Klebanoff MA, Cole SR (2008) Use of multiple imputation in the epidemiologic literature. Am J Epidemiol 168(4):355-357

Publisher's note Springer Nature remains neutral with regard to jurisdictional claims in published maps and institutional affiliations. 